\title{
Influence of single and multiple onset distractors on visual search for singleton targets
}

\author{
ARTHUR F. KRAMER, NICHOLAS D. CASSAVAUGH, \\ DAVID E. IRWIN, and MATTHEW S. PETERSON \\ Beckman Institute, University of Illinois, Urbana, Illinois \\ and \\ SOWON HAHN \\ University of California, Riverside, California
}

\begin{abstract}
In three experiments, we examined attentional and oculomotor capture by single and multiple abrupt onsets in a singleton search paradigm. Subjects were instructed to move their eyes as quickly as possible to a color singleton target and to identify a small letter located inside of it. In Experiment 1, taskirrelevant sudden onsets appeared simultaneously on half the trials with the presentation of the color singleton target. Response times (RTs) were longer when onsets appeared in the display regardless of the number of onsets. Eye-scan strategies were also disrupted by the appearance of the onset distractors, although the proportion of trials on which the eyes were directed to the onsets was the same regardless of the number of onsets. In Experiment 2, we manipulated the time of presentation of two taskirrelevant onsets in order to further examine whether multiple onsets would be attended and fixated prior to attending a color singleton target. Again, subjects made a saccade to a task-irrelevant onset on a substantial proportion of trials prior to fixating the target. However, saccades to the second onset were rare. Experiment 3 served as a replication of Experiment 1 but without the requirement for subjects to move their eyes to detect and identify the singleton target. The RT results were consistent with those in Experiment 1; dual onsets had no larger an effect on response speed than single onset distractors. These data are discussed in terms of the interaction between top-down and bottom-up control of attention and the eyes.
\end{abstract}

It is now well established that transient changes in the visual field and in particular the occurrence of new objects can capture attention. For example, Yantis and colleagues (Remington, Johnston, \& Yantis, 1992; Yantis \& Jones, 1991; Yantis \& Jonides, 1984) have performed a number of studies in which subjects search for a predefined target letter that could appear among other letters in a display. In each display, all but one of the letters were constructed by removing segments of figure-eight premasks. These letters were referred to as nononset stimuli. In addition, one new letter was added to the display concurrently with the removal of segments of the figure-eight premasks. This new letter was referred to as an onset. Although, in these experiments, the onset letter was no more likely to be the target than any of the other letters (i.e., the onset letter was the target $1 / n$ trials, with $n$ being equal to the total number of letters in a display), when the onset letter was the target, search performance was fast and

This research was supported by Grant AG14966 from the National Institute on Aging and a cooperative research agreement with the Army Research Laboratory (DAAL01-96-2-0003). We thank Shawn Bolin and Jay Peterson for their assistance in running subjects. Requests for reprints should be sent to A. Kramer, Beckman Institute, University of Illinois, 405 North Mathews Avenue, Urbana, IL, 61801 (e-mail: akramer@s.psych.uiuc.edu). independent of the number of letters in the display. These data have been interpreted as evidence that the onset is attended first - that is, that abrupt onsets capture attention.

More recently, Yantis and Hillstrom (1994; see also Hillstrom \& Yantis, 1994) asked whether onsets per se (i.e., luminance increments) or instead new objects were responsible for the capture of attention observed in previous studies. To this end, they performed a series of experiments in which they equated the luminance of onset and nononset stimuli by using texture, motion, and binocular disparity to differentiate stimuli from the background. Subjects in their study performed a search task (looking for the letter $\mathrm{H}$ or $\mathrm{U}$ ) in displays of four letters, three of which were nononsets defined by removing line segments from figure-eight premasks. There was always at least one onset letter in the display, and the target was the onset in $1 / n$ trials where $n$ is the display size. In all conditions, RT was faster to new (onset) targets than to old (nononset) targets, even though the onsets and nononset stimuli were equiluminant. Thus, it would appear that new objects rather than luminance increments capture attention (Yantis, 1996; Yantis \& Hillstrom, 1994).

In other studies, the boundary conditions on the phenomenon of attentional capture have been examined. For example, Yantis and Jonides (1990; see also Theeuwes, 1991) found that precuing the location of a target would 
override the ability of onsets or new objects to capture attention. Martin-Emerson and Kramer (1997) reported that the magnitude of attentional capture decreased with increasing complexity of the premasks, which were used to create the nononset items (see also Miller, 1989). Finally, Folk, Remington, and Johnston (1992, 1993; see also Folk \& Remington, 1998, 1999; Folk, Remington, \& Wright, 1994) have argued that the effectiveness of onsets or new objects to capture attention is modulated by attentional control settings.

Although attentional capture has traditionally been defined in terms of patterns of reaction time and accuracy data in visual search or cuing studies, recent studies performed in our laboratory have also examined the influence of capture on oculomotor control (Irwin, Colcombe, Kramer, \& Hahn, 2000; Kramer, Hahn, Irwin, \& Theeuwes, 1999, 2000; Theeuwes, Kramer, Hahn, \& Irwin, 1998; Theeuwes, Kramer, Hahn, Irwin, \& Zelinsky, 1999). For example, Theeuwes et al. (1998) have shown that abrupt on sets in a singleton search task not only capture attention, but can also capture the eyes. They asked subjects to search for a color singleton (i.e., a uniquely colored object) in an array of six circles arranged in an imaginary circle around fixation. The circles contained small figure-eight premasks at their centers. The initial display was of six gray circles with premasks and a central fixation cross. After $1,000 \mathrm{msec}$, the color of all but the target circle changed to red, and segments of the premasks were removed to create letters (E, F, H, S, P, and $\mathrm{U}$ for the distractors; $\mathrm{C}$ or reversed $\mathrm{C}$ for the target). At the time of the color change, on a subset of trials, they presented an equiluminantred abrupt onset circle in a location not previously occupied by a circle. The subject's task was to look at the gray target circle (i.e., the uniquely colored object or color singleton) and report via a keypress whether the target letter was a $\mathrm{C}$ or a reversed $\mathrm{C}$. The onset was always irrelevant to the task. The results showed a saccade in the direction of the irrelevant abrupt onset on a substantial number of trials, indicating that attention was captured on those trials.

An interesting question and one that we focus on in the present study is the effect of presenting multiple abrupt onset distractors when the subject's goal is to search for a color singleton target. This question is important because it addresses the interaction of top-down guidance of attention to a target with stimulus-driven attentional capture by new but task-irrelevant objects in the visual environment. In other words, in our study, we examined how attention is prioritized in the face of opposing top-down and bottom-up influences on the visual system.

This question has received little study. Yantis and Johnson (1990; see also Yantis \& Jones, 1991) investigated a related issue in a nonsingleton search task, in which subjects searched for a letter target among heterogeneous letter distractors. In their studies, subjects were presented with from one to eight onsets along with one to eight nononset stimuli and were asked to determine whether a predefined target letter was present in the display. The target was an onset on half the experimental tri- als. Therefore, the presence of onsets predicted neither the identity nor the location of the target. Nonetheless, Yantis and Johnson (1990) obtained reaction time data that suggested that subjects would search through up to four onsets before searching through the nononset objects for the target. Furthermore, their studies were consistent with a temporally decaying priority tag model of onset capture in that manipulations that slowed processing resulted in decreases in the number of onsets that were attended before nononset stimuli. That is, although onsets appeared to have a higher processing priority than nononset stimuli, the priority tags for the onsets decayed over time.

Yantis and Johnson's (1990; see also Yantis \& Jones, 1991) study clearly suggests that multiple onset stimuli have conditional priority over nononset stimuli in nonsingleton search (i.e., search for a target that is not uniquely defined by color, motion, form, etc.). Indeed, it would appear that up to four onset stimuli are processed prior to the processing of nononset stimuli under these conditions, despite the fact that the target is no more likely to be an onset than a nononset stimulus.

In the present study, we asked whether similar prioritization effects would be observed, for reaction time as well as eye movements, when additional top-down guidance can be employed to identify the target (i.e., when a target is defined by a unique feature, e.g., a gray target among red distractors; Treisman \& Sato, 1990; Wolfe, 1994) and when the onset distractors are task irrelevant (i.e., when onsets never serve as the target). We already know that a single task-irrelevant onset can capture attention and the eyes during search for a singleton target (Irwin, Colcombe, et al., 2000; Kramer et al., 1999, 2000; Theeuwes et al., 1998; Theeuwes et al., 1999). In the study reported here, we asked whether onset priority extends to multiple onsets in these conditions as it does in nonsingleton search (Yantis \& Johnson, 1990).

\section{EXPERIMENT 1}

To examine the effects of multiple onsets on singleton search we utilized a paradigm similar to that employed by Theeuwes et al. (1998; see also Irwin, Colcombe, et al., 2000; Kramer et al., 1999), in which subjects were initially presented with a number of figure-eight premasks inside of gray circles arranged around the periphery of an imaginary circle. After a brief period of time, all of the circles but one turned red. Subjects were instructed to move their eyes to the gray circle as quickly as possible and to determine whether a $\mathrm{C}$ or reversed $\mathrm{C}$ was present. In approximately $50 \%$ of the trials, either one or two onsets (see Figure 1) the same color as the nononset distractors, were presented simultaneously with the color change, which defined the target. The onsets never served as the target.

The main question addressed in this study was whether and to what extent the appearance of two new, yet taskirrelevant objects would disrupt the planning and execution of the goal-directed saccade toward the singleton target. It seemed conceivable that one or more of four possible outcomes might be observed. First, if Yantis and 

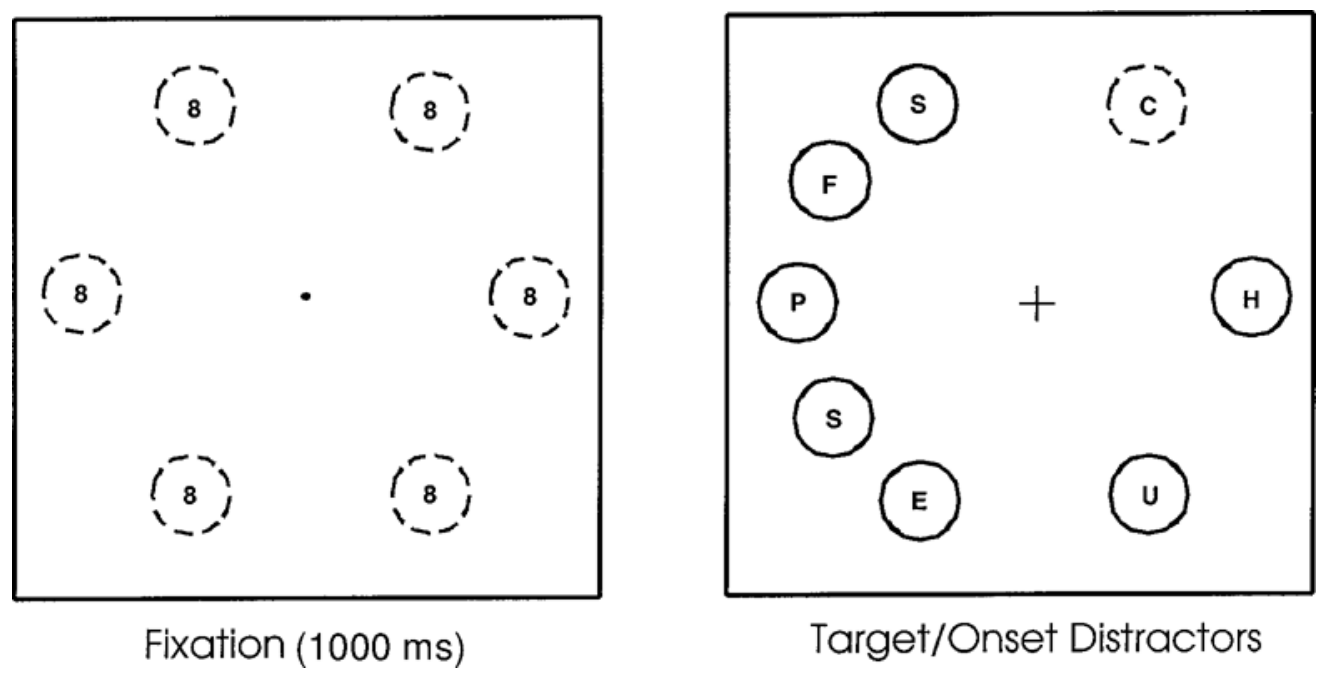

Figure 1. A graphic illustration of the displays and temporal sequence employed in Experiment 1. In the actual display, the figure eights and letters were created from block-like stimuli. The dashed lines represent gray circles and the solid lines represent red circles. This display illustrates a double onset 90-150 trial.

Johnson's (1990) findings of onset prioritization in nonsingleton search generalize to singleton search, it seemed likely that the eyes would move to both onset distractors before moving to the singleton target. However (and second), if top-down influences modulate attention capture, it seemed possible that the eyes would move to only one of the onset distractors before moving to the singleton target, producing a similar pattern of results to that obtained in the single onset studies performed by Theeuwes et al. (1998; see also Irwin, Colcombe, et al., 2000; Kramer et al., 2000). This might occur if the priority tag for the second onset distractor decayed below the top-down activation level of the singleton target while the subject was executing a saccade to the first onset distractor. Third, it seemed possible that the effects of the two distractors might cancel (Yantis \& Johnson, 1990, Model 1), which would result in a reduction or elimination of capture of the eyes on the dual-onset trials. Finally, it seemed possible that we would observe saccadic averaging, in which the two distractors would tend to pull the eyes toward their imaginary center of gravity (Aitsebaomo \& Bedell, 2000; Findlay, 1997; Viviani \& Swensson, 1982). It should be noted that due to the arrangement of the display, the two onset distractors always surrounded a nononset circle, which would have generally been the center-of-gravity location for the three-circle group. Thus, saccadic averaging would result in the initial saccade's being directed to the nononset object, which was interspersed between the two onset distractors.

\section{Method}

Subjects. The subjects were 8 University of Illinois undergraduate students ( 4 male, 4 female) and 1 male graduate student. Experimenter error resulted in the loss of 1 subject. The final set of 8 subjects consisted of 3 female undergraduate students (mean age $=$ $20.0 \mathrm{yrs}$ ), 4 male undergraduate students (mean age $=21.5 \mathrm{yrs}$ ), and
1 male graduate student (age $=34$ yrs). All subjects reported normal or corrected-to-normal vision.

Apparatus. A Gateway Pentium 150-MHz computer with a 19in. SVGA color monitor was used to present the stimuli, control the timing of the experimental events, and record subjects' reaction times (RTs). Eye movements were recorded with an Eyelink tracker (SR Research) with $250 \mathrm{~Hz}$ temporal resolution and a $0.2^{\circ}$ spatial resolution. The system uses infrared video-based tracking technology to compute the center and size of the pupils in both eyes. An infrared head tracking system tracked head motion. Even though head motion was measured, the head was stabilized by means of a chinrest located $80 \mathrm{~cm}$ from the monitor.

Stimuli. The stimuli consisted of six gray circles $\left(3.7^{\circ}\right.$ in diameter) arranged on an imaginary circle with a radius of $12.6^{\circ}$ of visual angle. The circles were arranged in the 1,3,5,7,9, and 11 o'clock positions on a clock face, resulting in a separation of $60^{\circ}$ of arc between each circle. Each of the circles contained a figure-eight premask $\left(0.4^{\circ} \times 0.2^{\circ}\right)$. A $0.3^{\circ} \times 0.3^{\circ}$ fixation star was presented in the center of the display. The initial display remained for $1,000 \mathrm{msec}$ and then changed. The fixation star changed to a cross, all but one of the circles changed to red, and line segments were removed from the figure-eight premasks to form letters. In the onset conditions, additional circles appeared at one or two of the other positions on the imaginary circle not already occupied by a circle (i.e., the 2,4 , 8 , or 10 o'clock position). The task was to determine whether the letter in the gray circle was a $\mathrm{C}$ or a reversed $\mathrm{C}$. The subjects responded by pressing the "z" or "/" key on the computer's keyboard. The mapping of response keys to the $\mathrm{C}$ or reversed $\mathrm{C}$ was counterbalanced across subjects. The letters inside of the red circles were response neutral distractor letters randomly sampled without replacement from the set of S, H, E, P, F, and U. The red and gray circles were matched for luminance $\left(24 \mathrm{~cd} / \mathrm{m}^{2}\right)$. Since the letters were very small, the subjects had to make a saccade to the gray circle (i.e., the color singleton) to identify the target letter.

In the onset conditions, additional circles (identical to the other red circles) appeared with distractor letters inside. There were two types of onset condition: single onset, in which only one circle was added, and dual onset, in which two circles were added. There were also control trials (nononset trials) in which the additional circles were displayed throughout the trial rather than appearing as a sudden onset after the first $1,000 \mathrm{msec}$. Taking the fixation point as the 
Table 1

Mean Reaction Times and Standard Deviations (in Milliseconds) for Onset and Nononset Distractors in Each Condition in Experiment 1

\begin{tabular}{llrlrr}
\hline & \multicolumn{4}{c}{ Condition } \\
\cline { 2 - 3 } \multicolumn{1}{c}{ Trial Type } & \multicolumn{2}{c}{ Abrupt Onset } & & \multicolumn{2}{c}{ No Onset } \\
\cline { 2 - 3 } \cline { 5 - 6 } & RT & $S D$ & & RT & $S D$ \\
\hline Double $150^{\circ}-90^{\circ}$ & 867 & 90 & & 805 & 75 \\
Double $90^{\circ}-90^{\circ}$ & 879 & 80 & & 821 & 124 \\
Single $150^{\circ}$ & 921 & 133 & & 851 & 118 \\
Single $90^{\circ}$ & 898 & 120 & & 857 & 129 \\
\hline
\end{tabular}

center of the imaginary circle, single onsets were presented either three clock positions away from the color singleton target, describing an angle of $90^{\circ}$ of arc (the single- 90 condition), or five clock positions away, describing an angle of $150^{\circ}$ of arc (the single- 150 condition). Double onsets were presented either three clock positions in either direction from the target (the double 90-90 condition) or one was five positions away and the other was three positions away (the double 150-90 condition) from the target. In Euclidean distances, these figures corresponded to $19.4^{\circ}$ and $25.4^{\circ}$ of visual angle, respectively. The stimuli remained on the display until the subject made a response.

Design. The subjects participated in four different conditions over two experimental sessions. One session consisted of singleonset conditions in which an abrupt onset circle was added to the display simultaneously with the color change that defined the color singleton target and a control condition in which a seventh circle was displayed throughout the trial (i.e., it was not an abrupt onset). The other session consisted of dual-onset conditions in which two abrupt onset circles were added to the display simultaneously with the color singleton and a control condition in which all eight circles were displayed for the duration of the trial (i.e., the two additional circles were nononsets). The order of the sessions was counterbalanced across subjects. The order of trials was randomized within each block. The stimuli were balanced for ipsilateral and contralateral presentation of distractors in relation to the targets.

The subjects performed five experimental blocks with 56 trials each for a total of 280 experimental trials per session. Each block contained 28 control and 28 onset trials. Targets were presented randomly at each of the four oblique positions. Because fewer muscles are involved in horizontal and vertical eye movements (thus creating a potential difference in movement time between "straight" and oblique eye movements), the 12,3,6, and 9 o'clock positions were never used for the target.

Procedure. Before starting the experiment, the headband of the Eyelink tracker with the infrared light source and camera was strapped into position on the subject's head. A chinrest was used to stabilize the head. The subjects were asked not to make any (large) head movements. The infrared source and the eye camera were adjusted until there was a clear corneal reflection in both eyes. After setting the threshold for detecting the pupil, the Eyelink system was calibrated. The subjects had to fixate nine calibration targets that were presented in a $3 \times 3$ grid in a random order across the monitor. As soon as a target was fixated, the next target appeared and the subject moved their eyes to fixate it. Once the calibration procedure was successfully completed, the experiment began.

The subjects served in two experimental sessions that lasted approximately $1 \mathrm{~h}$ each. They were instructed to maintain their eyes on fixation prior to the start of a trial. On each trial, the eye position was recalibrated to center so that reliable eye-movement measurements could be obtained. Following fixation, the subjects pressed the spacebar on the computer keyboard to initiate the trial. The trial would not start unless the eyes were at fixation and the spacebar was pressed. The display of six gray circles (or seven or eight on control trials) with figure-eight premasks inside was then presented for 1,000 msec. All but one of the circles then changed to red, and onset distractor(s) appeared on $50 \%$ of the trials. The subjects were instructed to move their eyes to the gray circle as soon as they detected the color change (and the change of the fixation star into a fixation cross) and to make one response if they detected a $\mathrm{C}$ and another response if they detected a reversed $\mathrm{C}$. The subjects heard a low $(200-\mathrm{Hz})$ tone following an incorrect response. No tone was presented for correct responses. The subjects were provided with feedback on their speed and response accuracy following each block of trials. The subjects were allowed to rest after each block. The rest period was self-terminated. The subject pressed the spacebar to start the next block.

\section{Results}

Discarded data. The first block of trials for each session was considered a practice block, and, therefore, those data were not included in the analyses. Of the remaining trials, $1.8 \%$ were removed due to incorrect responses, $0.17 \%$ were removed because the RT was less than $100 \mathrm{msec}$, and $16.7 \%$ were removed due to missing eye data.

Manual RT. RTs and standard deviations (SDs) are presented in Table 1. The data were analyzed with a twoway repeated-measures analysis of variance (ANOVA) with trial type (single-90, single-150, double 90-90, and double 150-90) and condition (onset vs. nononset) as within-subjects factors. RTs were slower overall when sudden onsets appeared in the display than when the additional circles were not sudden onsets $[F(1,7)=33.7, p<$ $.01]$. Neither the main effect of trial type nor the interaction of trial type $\times$ condition was significant.

Accuracy was uniformly high, exceeding $94 \%$ in all conditions and trial types. Although accuracy was slightly lower in onset conditions when the eyes initially went to the distractor (96.2\%) as compared with when the eyes directly went to the target $(99.0 \%)$, the difference was not statistically significant $(p>.50)$. No other main effects or interactions were significant for response accuracy.

Consistent with previous research (Irwin, Colcombe, et al., 2000; Kramer et al., 1999, 2000; Theeuwes et al., 1998; Theeuwes et al., 1999), the subjects misfixated the onset distractor(s) on a substantial number of trials (see the section on saccade path below). Because it was necessary to fixate the target in order to identify it (due to its small size), it is of interest to determine the extent of RT increase that is incurred when the subject's eyes go first to an onset distractor before moving to the color singleton target.

RTs were sorted on the basis of whether the eyes first went to an onset or directly to the target. These data were submitted to a two-way ANOVA with trial type (single-90, single-150, double 90-90, and double 150-90) and initial eye path (to target or to distractor) as within-subjects factors. Mean RTs were $942 \mathrm{msec}$ when the eyes went first to an onset distractor and $832 \mathrm{msec}$ when the eyes went directly to the color singleton target $[F(1,7)=11.8, p<.01]$. No other effects or interactions approached significance for the analysis of RTs sorted on the basis of the direction of the initial eye movement. 

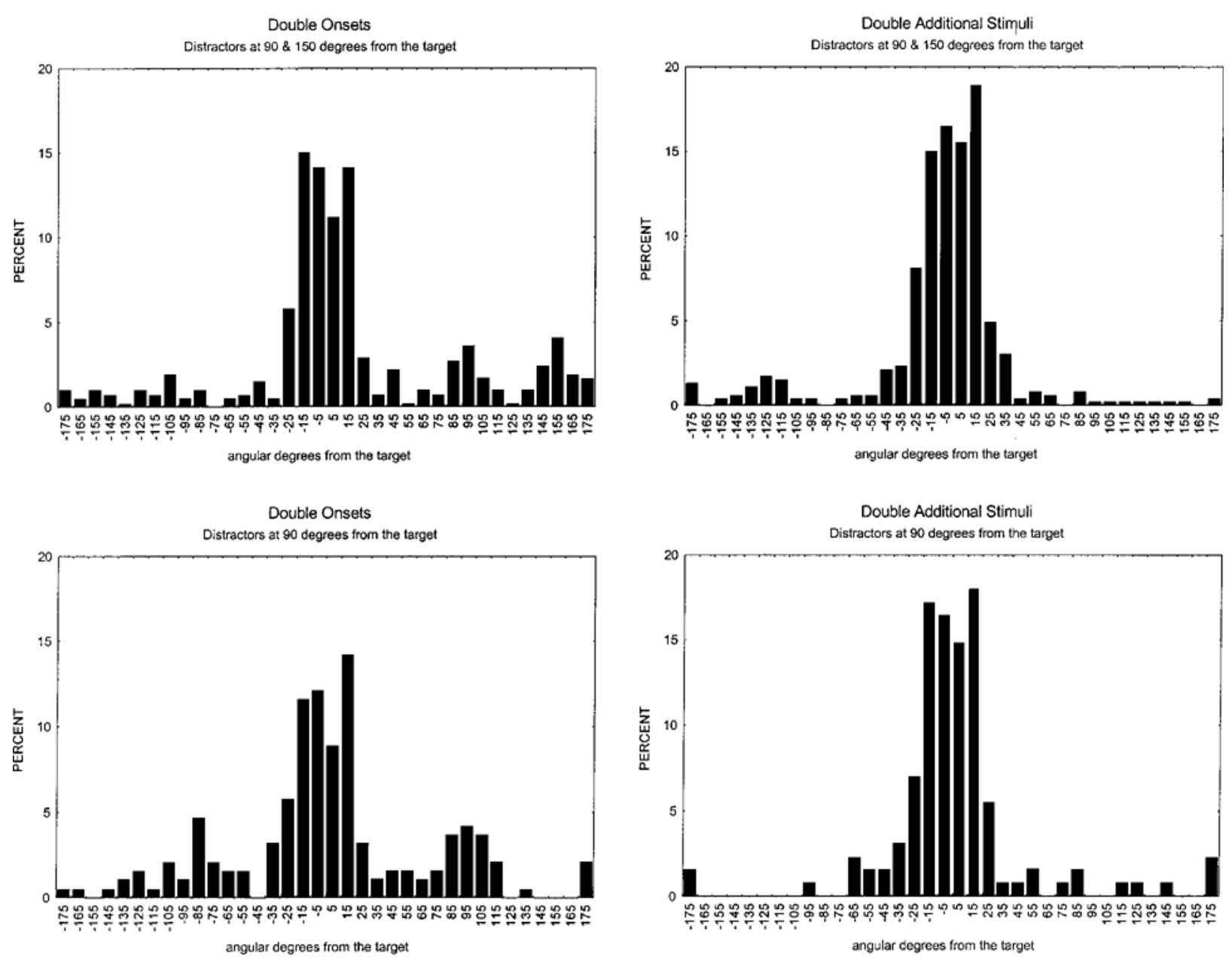

Figure 2. Histograms for the control (double additional stimuli) and onset conditions (double 90-90 and double 150-90) that illustrate the maximal angular deviation from a straight line path from fixation to the position of the target on each of the initial saccades in Experiment 1. These data represent all of the initial saccades for each of the subjects in the study.

Finally, we examined whether RTs on the nononset control trials $($ mean $=830 \mathrm{msec}$ ) differed from RTs on the onset trials when the eyes went directly to the singleton target (mean $=836 \mathrm{msec}$ ). Slower RTs on the onset trials on which the eyes went directly to the target than on the control trials would suggest an attentional capture cost that cannot be accounted for by eye movement capture. However, this difference was not statistically significant $(p>.65)$.

Saccade path. Three thresholds were used for saccade detection: movement distance, velocity, and acceleration. An eye movement was considered a saccade either when the movement distance exceeded $0.2^{\circ}$ and velocity exceeded $30 \mathrm{deg} / \mathrm{sec}$, or when the movement distance exceeded $0.2^{\circ}$ and the acceleration exceeded $8,000 \mathrm{deg} / \mathrm{sec}^{2}$. Initial saccades were considered to have moved in the direction of a target or distractor if the saccade's maximum angle of deviation from a straight line to the item was $\pm 30^{\circ}$.

For initial saccades, the maximum angular deviation from a straight line to the target was calculated for all tri- als. Figure 2 shows the distributions of these data for the dual onset conditions, and Figure 3 shows the same data for single onset conditions. Consistent with our previous work involving single onset distractors, initial saccades in control (nononset) conditions tended to move in the general direction of the target. However, a substantial percentage of initial saccades in the onset conditions went toward a distractor. The mean proportion of initial saccades to distractors in the single- 90 and single- 150 onset distractor conditions were $31 \%$ and $25 \%$, respectively. For the double 90-90 and double 150-90, the mean proportions were $26 \%$ and $21 \%$, respectively. These data show clear evidence of capture. The data were submitted to a two-way ANOVA with trial type (single-90, single150, double 90-90, and double 150-90) and condition (onset distractors vs. nononset distractors) as factors. Main effects were present only for condition $[F(1,56)=$ $33.63, p<.01]$. The eyes tended to move to onset distractors in $26 \%$ of onset trials, but moved to nononset distractors in only $5 \%$ of nononset trials. It is noteworthy that no significant difference was present for trial type, 

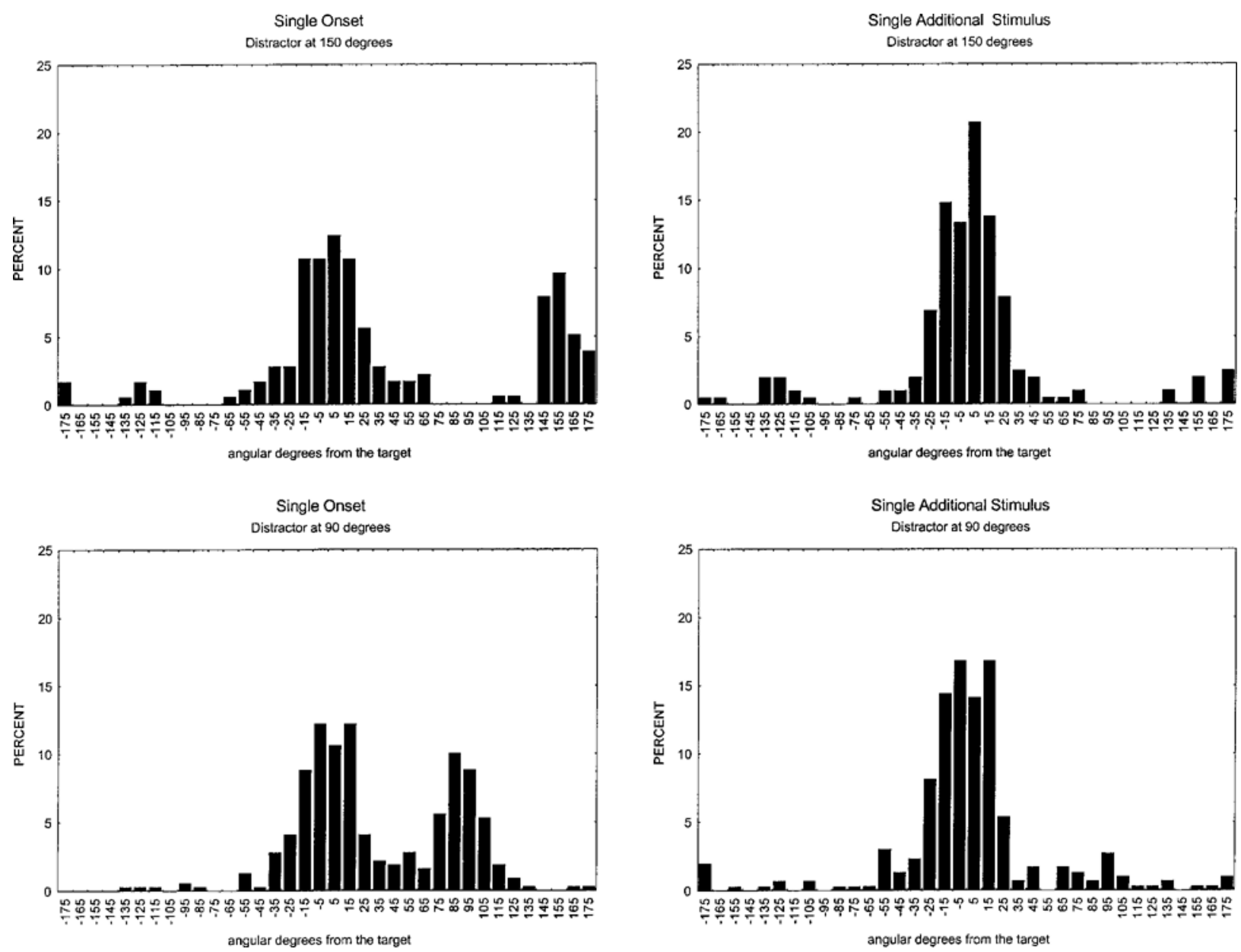

Figure 3. Histograms for the control (single additional stimuli) and onset conditions (single-90 and single-150) that illustrate the maximal angular deviation from a straight line path from fixation to the position of the target on each of the initial saccades in Experiment 1 . These data represent all of the initial saccades for each of the subjects in the study.

and there was no interaction of trial type with condition. Multiple abrupt onsets did not capture attention or the eyes more often on the first eye movement than single abrupt onsets. Indeed, the nonsignificant trend was in the opposite direction.

If Yantis and Johnson's (1990; see also Yantis \& Jones, 1991) finding that more than one abrupt onset will be attended before nononset objects are attended can be generalized from nonsingleton to singleton search, then we should observe that both onset distractors are fixated prior to the subjects' fixating the color singleton target on a significant proportion of the dual-onset trials. To examine this possibility, all trials categorized as having an initial saccade in the direction of an onset distractor circle were analyzed to determine the direction of the second saccade. Of the trials in the dual-onset (double 150-90 and double 90-90) conditions in which the initial saccade went toward an onset circle, only $4.2 \%$ resulted in a second saccade that went toward the other onset circle. In the control trials with nononset distractors, when the initial eye movement went to an additional distractor only $4.5 \%$ had a second saccade toward the other distractor item. An independent measures $t$ test showed no significant difference between conditions (onset vs. nononset control trials) in the proportion of second saccades to a distractor $[t(7)=0.08]$, indicating that saccades to the second distractor were not due to abrupt onset capture of attention. Thus, our results do not extend the findings of Yantis and Johnson, obtained in a nonsingleton search paradigm, that multiple onsets will capture attention before attention is directed to a nononset object in singleton search. This issue will be examined in detail in the Discussion section.

Our results also provide little support for the hypothesis that the eyes would move to a center-of-gravity location between the two distractor circles in the dual-onset trials. To test this possibility, the percentage of initial saccades that went to a center-of-gravity location was calculated for the dual-distractor conditions. ${ }^{1}$ If multiple onsets encourage saccades to go towards the center-ofgravity between two onset distractors, there should be more initial saccades to a center-of-gravity location when the distractors were onsets than when they were non- 
Table 2

Mean Saccade Latencies (in Milliseconds) and Standard Deviations for Trials With Onset Distractors in Experiment 1

\begin{tabular}{|c|c|c|c|c|c|c|c|c|}
\hline \multirow[b]{3}{*}{ Eye Path } & \multicolumn{8}{|c|}{ Trial Type } \\
\hline & \multicolumn{2}{|c|}{ Single $90^{\circ}$} & \multicolumn{2}{|c|}{ Single $150^{\circ}$} & \multicolumn{2}{|c|}{ Double $150^{\circ}-90^{\circ}$} & \multicolumn{2}{|c|}{ Double $90^{\circ}-90^{\circ}$} \\
\hline & RT & $S D$ & RT & $S D$ & RT & $S D$ & RT & $S D$ \\
\hline Target & 270 & 64 & 28 & 76 & 278 & 48 & 291 & 55 \\
\hline Distractor & 216 & 53 & 229 & 58 & 259 & 46 & 234 & 30 \\
\hline
\end{tabular}

onsets. In fact, the opposite was true, with onsets generating saccades to a center-of-gravity location on $1.7 \%$ of trials as compared with $2.4 \%$ of trials for nononsets. A two-way ANOVA was performed with trial type (double 150-90, double 90-90) and condition (onsets vs. nononsets) as factors. No main effects or interactions were significant. On the basis of these analyses, we conclude that multiple onset distractors do not result in saccades to the center of gravity of the onsets.

Saccade latency. The average saccade latencies were submitted to a two-way ANOVA with trial type (single90, single-150, double 90-90, or double 150-90) and eye path (first saccade toward the target or first saccade toward a distractor) as within-subjects factors. Only trials with abrupt-onset distractors were analyzed. No significant main effects or interactions were present. Mean saccade latencies are shown in Table 2 by trial type and eye path. Although the eye path effect is not significant, it is apparent from the data that the trend was toward shorter latency when the eyes went toward the distractor $[F(1,7)=$ $4.2, p<.08]$. This suggests that onsets elicited especially rapid saccades.

Fixation duration after a saccade to the onset distractor. In our previous research (Irwin, Colcombe, et al., 2000; Kramer et al., 1999, 2000; Theeuwes et al., 1998; Theeuwes et al., 1999), we found that fixations that occur between the initial saccade to an onset distractor and subsequent movement of the eyes to a color singleton target were quite brief. Fixation durations were generally too short to permit programming of a second eye movement during the fixation (which typically takes a minimum of 150 msec; see Becker, 1991; Findlay, 1997; Salthouse \& Ellis, 1980). These data were interpreted as indicating that two saccades were programmed simultaneously: a rapid reflexive saccade to a distractor and a sometimes slower goal-directed saccade to the target (see also Becker \& Jurgens, 1979; Henderson \& Ferreira, 1990; Reichle, Pollatsek, Fischer, \& Rayner, 1998). The eyes would move directly to the target if the goal-directed saccade program finished first, but would move instead to the onset distractor if the reflexive-saccade program finished first before moving to the target upon completion of the goal-directed saccade program.

To examine this issue, in the present study, the average fixation durations for the onset distractor trials were submitted to a two-way ANOVA with trial type (single-90, single-150, double 90-90, or double 150-90) and eye path (first saccade toward the target or first saccade toward a distractor) as within-subjects factors. The fixation durations for fixations after a first saccade to an onset are graphed in Figure 4. As with saccade latencies, trials in which the eyes did not go to either to the target or to an onset were eliminated from the analysis, as were control trials without onsets. Fixation durations were significantly shorter when the eyes went first to a distractor $(113 \mathrm{msec})$ than when they went to the color singleton target $(189 \mathrm{msec})[F(1,7)=29.2, p<.01]$. There was no main effect of trial type and the interaction of trial type $X$ eye path was not significant. These findings support the hypothesis that the reflexive and goal-directed saccades are likely programmed in parallel, since the fixation duration in the trials on which the eyes went to a distractor was too short to have allowed the subject to program another eye movement.

\section{Discussion}

Experiment 1 was conducted in order to examine the influence of single and multiple onset distractors on visual search for color singleton targets. Consistent with previous research with single onset distractors (Irwin, Colcombe, et al., 2000; Kramer et al., 1999, 2000; Theeuwes et al., 1998; Theeuwes et al., 1999), search performance was disrupted on approximately $25 \%$ of the trials, when abrupt onsets appeared in the display as evidenced by increased manual RTs and misdirected saccades to the location of an onset. RTs were longer in all trial types when onset distractors were present in the display than when distractors were not onsets. The increase in RT was due, in large part, to the time required to reorient attention and the eyes after making an erroneous saccade to a distractor.

A main goal of Experiment 1 was to determine whether multiple onsets would have greater attentional priority than nononsets, as evidenced by a greater percentage of second saccades' being directed to an onset distractor than being directed to a nononset distractor in the control condition. The eye movement data did not support prioritization of multiple onsets. Saccades to the second onset were infrequent and did not differ from the percentage of saccades to the nononset distractors in the control conditions.

As previously discussed, Yantis and colleagues (Yantis \& Johnson, 1990; Yantis \& Jones, 1991) found that four onsets were attended prior to attending nononset objects. However, in their studies, subjects searched for a nonsingleton target (i.e., a target letter among heterogeneous letter distractors). In such a situation, top-down guidance of 
Single Onset

Trials Eyes Initially Went To the Onset

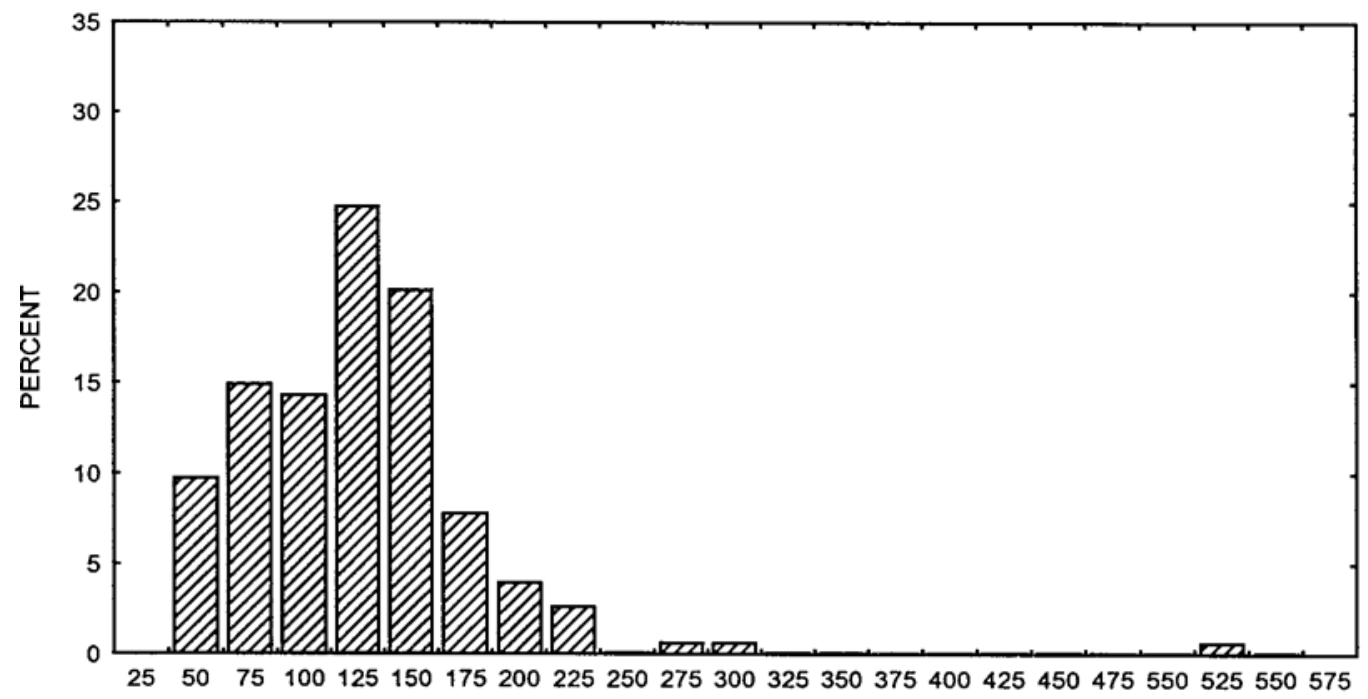

Double Onsets

Trials Eyes Initially Went To the Onsets

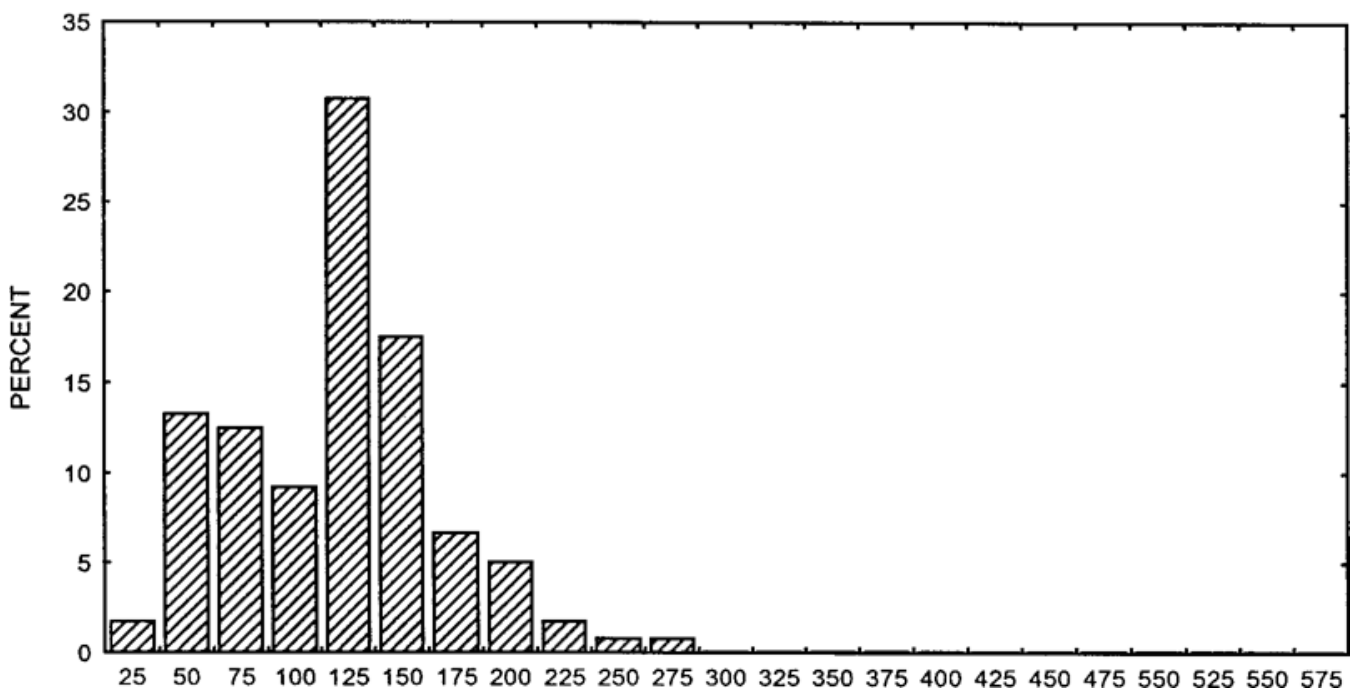

Figure 4. Fixation durations (in milliseconds) for the first fixation after an initial saccade to an onset distractor in Experiment 1.

attention (Treisman \& Sato, 1990; Wolfe, 1994) would be relatively ineffective due to the similarity of the target to the distractors. Therefore, the bottom-up signals generated by the onset objects would likely be unopposed by top-down activation of the target, even after attention had been initially directed to an object in the display.

On the other hand, top-down guidance of attention to the target in Experiment 1 might be quite effective given the dissimilarity of the target color from the color of the distractors. Indeed, the fact that initial saccades were directed to the singleton target on approximately $75 \%$ of the trials suggests that activation values for the target often exceeded those for the onset distractor. It also seems conceivable that the failure to observe saccades to the second onset in our paradigm may have been the result of decay of the priority tag for the onset. In such a case, it would be unlikely that the activation of the onset would exceed that of the color singleton target, thereby resulting in a saccade to the target on the great majority of trials. This issue is further addressed in Experiment 2.

Experiment 1 also enabled us to determine whether multiple onsets would result in either saccadic averaging or 
cancellation of saccades to either of the onset distractors. Evidence for saccadic averaging was not found. Saccadic averaging might have been observed in the form of more saccades to a center-of-gravity location (between the two distractors) on onset versus nononset trials. However, essentially the same number of saccades was made to the center-of-gravity location in both onset and nononset control trials.

Cancellation would be expected to result in fewer initial saccades to onset distractors (see Yantis \& Johnson, 1990, Model 1) on dual as compared with single onset trials. Interestingly, there was a nonsignificant trend toward fewer trials on which the eyes were initially directed to an onset distractor on double as compared with single onset trials. The eyes moved toward an onset distractor on $23.5 \%$ of the double and $28 \%$ of the single onset trials. This trend was examined further in Experiment 2 with additional subjects and control conditions. ${ }^{2}$

\section{EXPERIMENT 2}

Although the results obtained in Experiment 1 provided little support for the hypothesis that multiple onset distractors are prioritized over nononset objects during singleton search, it is conceivable that the priority tags for task-irrelevant onsets decay rapidly thereby reducing activation levels below that for the singleton target. Indeed, Yantis and Jones (1991) found that manipulations that delayed processing reduced the number of onsets that were attended before nononsets in nonsingleton search. In singleton search, one might expect the activation levels of onsets to decay below the activation level of the target relatively quickly thereby eliminating the ability of multiple concurrently presented onset distractors to capture attention and the eyes.

In an effort to potentially reduce the impact of the decay of priority tags for the abrupt onsets, we employed an eye movement contingent control procedure in Experiment 2. That is, we included two conditions in the present experiment, in which one onset distractor was presented simultaneously with the color change, which signaled the location of the singleton target, and the other onset was presented either during the first eye movement away from fixation (movement-contingentcondition) or when the eye came to rest at the end of the first saccade (stop-contingent condition). In both of these conditions, one onset distractor was presented later than the other onset distractor in an effort to lessen the impact of onset decay on the capture of attention and the eyes by multiple onsets. In another condition (dual-onset condition), both of the onset distractors were presented simultaneously with the color change, as in Experiment 1. Finally, two control conditions were included in the study. Either one (single nononset control) or two (dual nononset control) extra nononset distractors were added to the display at the beginning of the trial, as in Experiment 1.

If the failure to observe capture of attention and the eyes by the second onset distractor in Experiment 1 was due to decay of onset activation, we would expect to observe more frequent capture by the second onset in the movement- and stop-contingent conditions than in the dual-onset condition in the present experiment. This follows because the second onset is presented later in the two former conditions than it is in the dual-onset condition.

We also re-examined the cancellation hypothesis, which is that the simultaneous presentation of two onset distractors would cancel, thereby diminishing eye movement capture (Yantis \& Johnson, 1990, Model 1) by doubling the number of subjects in the present experiment as compared with Experiment 1. In Experiment 2, evidence for cancellation would be provided by fewer initial saccades' being directed to an onset in the dual-onset than in the movement-contingent(or stop-contingent)conditions.

\section{Method}

Subjects. The subjects were 15 University of Illinois students (5 male). The mean age of the students was 20.7 years. All subjects reported normal or corrected-to-normal vision.

Apparatus. The apparatus was the same as that employed in Experiment 1.

Stimuli. The stimuli were the same as those employed in Experiment 1 with the following exceptions. There were three experimental conditions: movement contingent, stop contingent, and dual onset. The onsets in the dual-onset condition both appeared at the time of the color change, which signaled the location of the singleton target. In the movement-contingent condition, the first distractor circle appeared at the time of the color change, but the second distractor did not appear until the eyes began the initial saccade from fixation. For our purposes, the initial eye movement was considered in progress when the eyes moved out of a circle centered on the fixation point and having a radius of 40 pixels $\left(1.7^{\circ}\right.$ of visual angle). The stop-contingent condition was similar to the movementcontingent condition, except that the second distractor circle did not appear until the eyes stopped moving at the end of the initial saccade from fixation. The eyes were considered to be stopped when they moved less than four pixels $\left(.20^{\circ}\right.$ of visual angle) in one refresh cycle of the eye tracker $(4 \mathrm{msec})$.

Two control conditions were included in which there were one or two additional circles in the initial display (before the color change), but no circles were added after the color change. These are referred to as the seven-item and eight-item nononset conditions.

Design. The three experimental conditions each comprised $25 \%$ of the total number of trials, with the two control conditions making up the remaining $25 \%$ equally. The order of trials was randomized within each block. The subjects performed three experimental blocks with 192 trials each for a total of 576 experimental trials per session. The targets were presented randomly at each of the four oblique positions. The distractors were presented randomly at each of the possible combined separations from the target, representing the possible separations between the distractors.

Procedure. The procedure for setting up and calibrating the eye tracker was equivalent to that used in Experiment 1 . The subjects served in two experimental sessions that lasted approximately $1 \mathrm{~h}$ each. They were instructed to maintain fixation prior to the start of a trial. On each trial, the eye position was recalibrated to center so that reliable eye movement measurements could be obtained. Once fixated, the subjects pressed the spacebar on the computer keyboard to initiate the trial. The trial would not start unless the eyes were at fixation and the spacebar was pressed. The display of gray circles with figure-eight premasks inside was then presented for 1,000 msec. During this time, a $400-\mathrm{Hz}$ tone sounded if the eyes moved away from fixation before the color change. All but one of the circles then changed to red. The subjects were instructed to move their eyes 
Table 3

Mean Reaction Times and Standard Deviations (in Milliseconds) for Onset and Nononset Distractors in Each Condition in Experiment 2

\begin{tabular}{llllll}
\hline & \multicolumn{4}{c}{ Trial Type } \\
\cline { 2 - 3 } \multicolumn{1}{c}{ Condition } & \multicolumn{2}{c}{$150^{\circ}-90^{\circ}$} & & $90^{\circ}-90^{\circ}$ \\
\cline { 2 - 3 } \cline { 5 - 6 } \multicolumn{1}{c}{ RT } & & & RT & $S D$ \\
\hline Single nononset & 778 & 119 & 770 & 113 \\
Double nononset & 788 & 144 & 760 & 114 \\
Double onset & 812 & 143 & 795 & 107 \\
Movement contingent & 810 & 118 & 808 & 111 \\
Stop contingent & 801 & 113 & 809 & 144 \\
\hline
\end{tabular}

to the gray circle as soon as they detected the color change (and the change of the fixation star into a fixation cross) and to make one response if they detected a $\mathrm{C}$ and another response if they detected a reversed C. The subjects heard a low $(200-\mathrm{Hz})$ tone following an incorrect response. No tone was presented for correct responses. The subjects were provided with feedback on their speed and response accuracy following each block of 192 trials. The subjects were allowed to rest after each block. The rest period was self-terminated by the subject's pressing the spacebar to start the next block.

\section{Results}

Discarded data. The first block of trials for each session was considered a practice block, and therefore those data were not included in the analyses. Of the remaining trials, $1.9 \%$ were removed due to incorrect responses, $.24 \%$ were removed because the RT was less than $100 \mathrm{msec}$, and $11.9 \%$ were removed due to missing eye data.

Manual RT. Mean RTs and SDs are presented in Table 3 . The data were analyzed with a two-way repeated measures ANOVA with trial type (90-90 or 150-90) and condition (dual-onset, movement-contingent,stop-contingent, single nononset, dual nononset) as within-subjects factors. RTs were slower in conditions when onset distractors were presented than in the single and dual nononset control conditions $[F(4,56)=11.4, p<.01$ for the main effect of condition and $p \mathrm{~s}<.01$ for post hoc comparisons between onsets and nononset conditions]. RTs did not differ among the different onset conditions nor between the two control conditions. Neither the main effect of trial type or the interaction of trial type $\times$ condition was significant. Accuracy of responding was uniformly high, exceeding $98 \%$ in all conditions and trial types. Neither the main effects nor the interactions were significant.

Consistent with the results of Experiment 1 and previous research (Irwin, Colcombe, et al., 2000; Kramer et al., 1999, 2000; Theeuwes et al., 1998; Theeuwes et al., 1999), the subjects misfixated the onset distractor(s) on a substantial number of trials (see the section on saccade path below). As in Experiment 1, RTs were sorted on the basis of whether the eyes first went to an onset or directly to the target. These data were submitted to a three-way ANOVA with trial type (90-90 or 150-90), condition (dual-onset, contingent-movement, or contingent-stop), and initial eye path (to target or to distractor) as within-subjects factors. Mean RTs were $884 \mathrm{msec}$ when the eyes went first to a distractor versus $757 \mathrm{msec}$ when the eyes went di- rectly to the color singleton target $[F(1,14)=216.4, p<$ $.01]$. No other effects or interactions approached significance for the analysis of RTs sorted on the basis of the direction of the initial eye movement.

Finally, we examined whether RTs on the nononset control trials $($ mean $=773 \mathrm{msec}$ ) differed from RTs on the onset trials when the eyes went directly to the singleton target $($ mean $=755 \mathrm{msec})$. Slower RTs on the onset trials on which the eyes went directly to the target than on the control trials would suggest an attentional capture cost, which cannot be accounted for by eye movement capture. However, this difference was not statistically significant $(p>.09)$. Indeed, the difference was in the opposite direction from what would be predicted if covert attention but not the eyes were captured by the occurrence of an onset distractor.

Saccade path. The thresholds used for saccade detection were identical to those employed in Experiment 1. For initial saccades, the maximum angular deviation from a straight line to the target was calculated for all trials. Figure 5 shows the distributions of these data for the $90^{\circ}-90^{\circ}$ distractor separation condition and Figure 6 shows the same data for $150^{\circ}-90^{\circ}$ distractor separation condition. Panels for the dual-onset, movement-contingent, stopcontingent, and dual nononset control conditions are included in each figure. The single nononset condition is not included in these figures, since the distributions were quite similar to that in the dual nononset condition. Consistent with the data obtained in Experiment 1, initial saccades in the nononset control conditions tended to move in the general direction of the target. However, a substantial percentage of initial saccades in the onset conditions went toward a distractor. The mean proportion of initial saccades to onset distractors in the dual-onset, movementcontingent, and stop-contingent conditions was $21 \%$, $25 \%$, and $26 \%$, respectively. This contrasts with only $4 \%$ and $5 \%$ of the initial eye movements to the extra distractors in the dual and single nononset conditions, respectively. Thus, like in Experiment 1, the eyes were captured by the abrupt onsets in each of the onset conditions.

These data were submitted to a two-way ANOVA with trial type (90-90 or 150-90) and condition (single nononset, dual-nononset, dual onset, movement contingent, or stop contingent) as within subjects factors. There was a main effect of condition $[F(4,56)=32.6, p<.01]$. Post hoc analyses indicate that the eyes went to the onsets more frequently in the movement-contingent and stop-contingent conditions than on the dual-onset conditions $(t \mathrm{~s}>$ $5.9, p$ s $<.01)$. This effect is particularly interesting since it (1) is the same as the nonsignificant trend for fewer saccades to the onsets on the double than on the single onset trials in Experiment 1 and (2) suggests that a small proportion of reflexive saccades to the onsets may indeed be canceled (Yantis \& Johnson, 1990, Model 1) when multiple onsets are simultaneously presented in a display. This follows since the two onset distractors were presented concurrently in the dual-onset condition, whereas the two distractors were presented sequentially in the movement- 

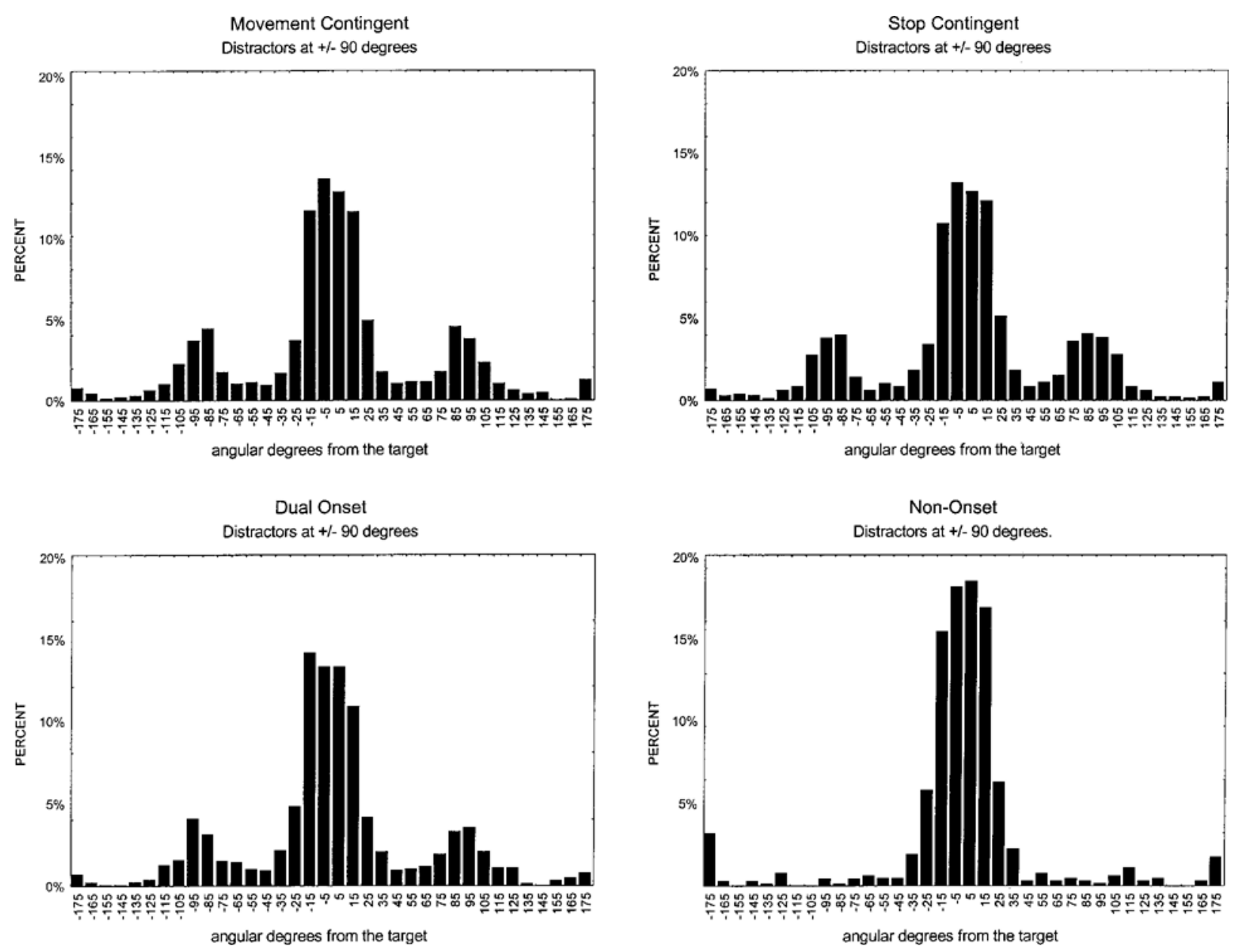

Figure 5. Histograms for the control (dual nononset) and onset conditions (movement contingent, stop contingent, and dual onset) for the $90^{\circ}-90^{\circ}$ target distractor separation that illustrate the maximal angular deviation from a straight line path from fixation to the position of the target on each of the initial saccades in Experiment 2. These data represent all of the initial saccades for each of the subjects in the study.

contingent and stop-contingent conditions in the present study.

In Experiment 1, we examined whether Yantis and Johnson's (1990; see also Yantis \& Jones, 1991) finding that more than one abrupt onset will be attended before nononset objects are attended can be generalized from nonsingleton to singleton search. Our data were not consistent with the multiple onset capture hypothesis. However, in the first experiment it is conceivable that the topdown activation afforded to the color singleton target along with the decay of the nonfixated onset distractor (on trials on which subjects initially fixated one of the distractors) might have substantially reduced the ability of the second onset distractor to capture the eyes and attention. Therefore, in Experiment 2, we included two conditions, the movement-contingent and stop-contingent conditions, in which the onsets were sequentially presented.

If our failure to observe multiple onset capture was due to onset decay in Experiment 1, we might expect to observe more evidence for multiple onset capture in the movement and stop-contingent conditions than in the dual-onset condition in Experiment 2. To examine this hypothesis, all trials categorized as having an initial saccade in the direction of an onset distractor circle (or a nononset distractor in the dual-nononset control condition) were examined to determine the direction of the second saccade. The proportion of second saccades directed to the onset distractor (or additional nononset object in the control condition), collapsed across trial type (i.e., 90-90 or 150-90), was less than $1 \%$ in each of the onset and control conditions. Therefore, these data suggest that the failure to observe multiple onset capture in Experiment 1 was not the result of the decay of activation tags for the onsets but instead was due to the increase of activation of the representation of the singleton target.

In Experiment 1, we tested the center-of-gravity hypothesis with the dual-onset trials. That is, we examined whether the eyes were more likely to be directed to the center of gravity on the onset than on the nononset control trials. No evidence for this hypothesis was found in 


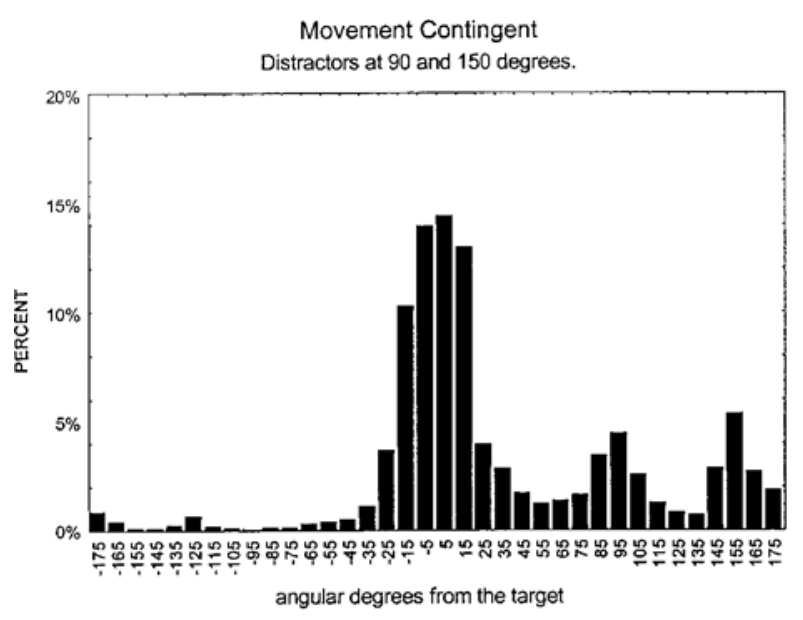

Dual Onset

Distractors at 90 and 150 degrees

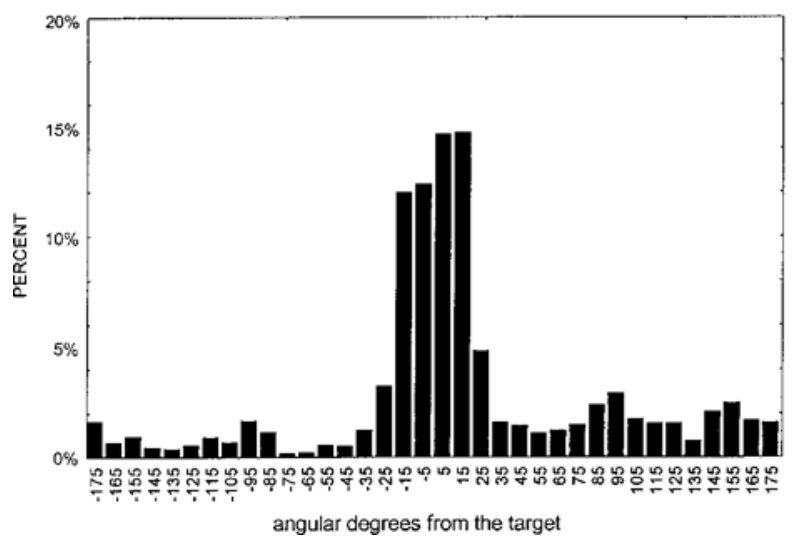

Stop Contingent

Distractors at 150 and 90 degrees

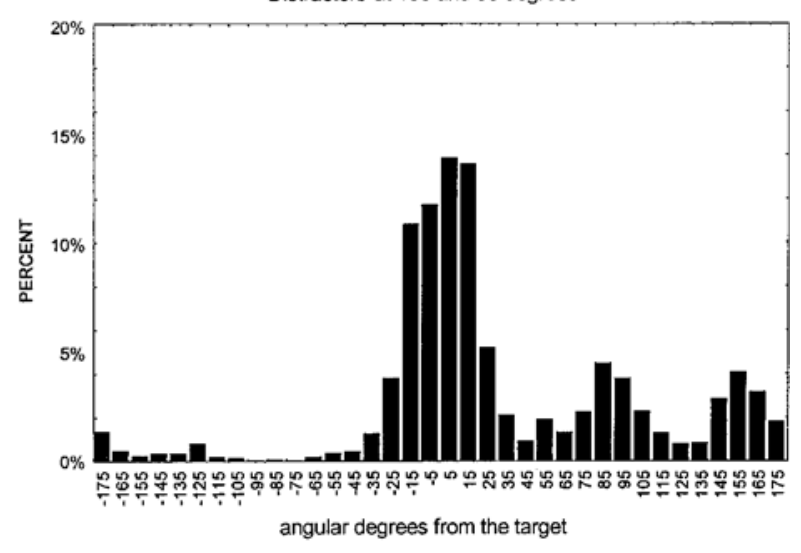

Non-onset

Distractors at 150 and 90 degrees

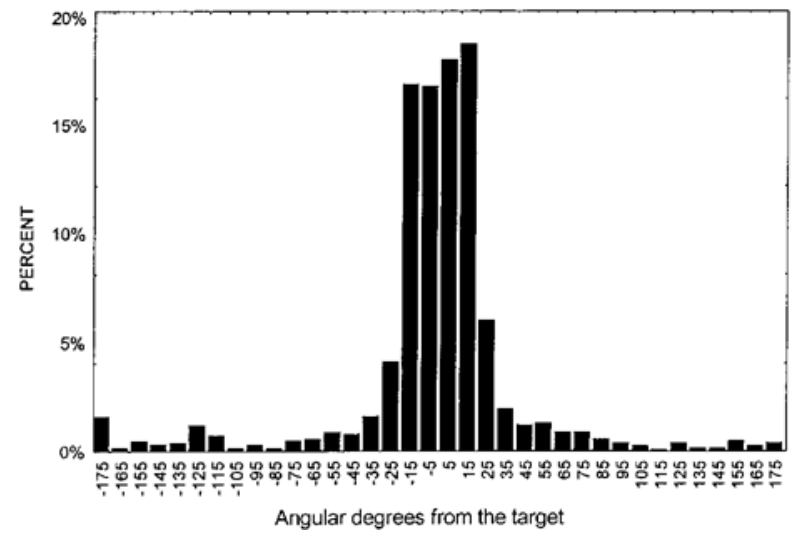

Figure 6. Histograms for the control (dual nononset) and onset conditions (movement contingent, stop contingent, and dual onset) for the $90^{\circ}-150^{\circ}$ target distractor separation that illustrate the maximal angular deviation from a straight line path from fixation to the position of the target on each of the initial saccades in Experiment 2. These data represent all of the initial saccades for each of the subjects in the study.

Experiment 1. The design of Experiment 2 allowed us to examine this hypothesis again with more statistical power. To test the hypothesis, the percentage of initial saccades that went to a center-of-gravity location was calculated for the dual distractor conditions. If multiple simultaneously presented onsets encourage saccades to go towards the center of gravity between two onset distractors, there should have been more initial saccades to a center-ofgravity location when the distractors were onsets than when they were nononsets. Indeed, this was the result that we observed. The subjects moved their eyes to a centerof-gravity location on $4.9 \%$ of the trials on which two taskirrelevant onsets were presented (double onset trials) as compared with $2.8 \%$ of the trials on which two additional nononset stimuli (double nononset trials) were presented. This difference was statistically significant $[F(1,14)=$ $7.9, p<.01]$. Thus, unlike Experiment 1 , a small but significant number of eye movements were directed to a distractor located midway between the onsets in the present study.
Saccade latency. The average saccade latencies were submitted to a three-way ANOVA with trial type (90-90 or 150-90), condition (dual onset, movement contingent, or stop contingent), and eye path (first saccade toward the target or first saccade toward a distractor) as withinsubjects factors. Only trials with abrupt-onset distractors were analyzed. Mean saccade latencies are shown in Table 4 by condition and eye path. A significant main effect was obtained for eye path $[F(1,14)=35.7, p<.01]$. Saccades directed to the color singleton target were slower than saccades initially directed to an onset distractor (199 vs. $223 \mathrm{msec}$, respectively). None of the other main effects or interactions were significant.

Fixation duration after a saccade to the onset distractor. In Experiment 1 and in previous research (Irwin, Colcombe, et al., 2000; Kramer et al., 1999, 2000; Theeuwes et al., 1998; Theeuwes et al., 1999), we found that fixations that occur between the initial saccade to an onset distractor and subsequent movement of the eyes to a color singleton target were quite brief-too short to 
Table 4

Mean Saccade Latencies (in Milliseconds) and Standard Deviations for Trials

With Onset Distractors in Experiment 2

\begin{tabular}{llllll}
\hline & \multicolumn{4}{c}{ Eye Path } \\
\cline { 2 - 3 } \cline { 5 - 6 } \multicolumn{1}{c}{ Condition } & \multicolumn{2}{c}{ To Target } & & \multicolumn{2}{c}{ To Distractor } \\
\cline { 2 - 3 } \cline { 5 - 6 } \multicolumn{1}{c}{} & RT & $S D$ & & RT & $S D$ \\
\hline Double onset & 223 & 25 & & 199 & 17 \\
Movement contingent & 221 & 26 & & 199 & 13 \\
Stop contingent & 224 & 25 & & 197 & 17 \\
\hline
\end{tabular}

permit programming of a second eye movement during the fixation.

To examine these data in the present study, the average fixation durations for the onset distractor trials were submitted to a three-way ANOVA with trial type (90-90 or 150-90), eye path (first saccade toward the target or first saccade toward a distractor), and condition (double onset, movement contingent, and stop contingent) as withinsubjects factors. Like Experiment 1, we found a significant effect of eye path $[F(1,14)=59.7, p<.01]$. Fixation durations were substantially shorter when the eyes were initially directed to an onset distractor $(108 \mathrm{msec})$ than when the eyes were directed to the color singleton target $(213 \mathrm{msec})$. Thus, these data, like those obtained in Experiment 1 , support the hypothesis that the reflexive and goal-directed saccades are likely programmed in parallel, since the fixation duration in the trials on which the eyes went to a distractor was too short to have allowed the subject to program another eye movement.

\section{Discussion}

Experiment 2 was conducted to further examine the interaction between top-down and bottom-up factors in the control of attention and the eyes during visual search for a singleton target. We reasoned that our failure to observe multiple onset capture in Experiment 1 might have been due to decay of the priority tag for one onset as the other onset was being attended and fixated.

In order to examine this issue, we employed an eye movement contingent control procedure to delay the presentation of the second onset so that it was presented either during the initial saccade (movement-contingent condition) or when the first saccade was completed (stopcontingent condition). Such a procedure should serve to enhance the activation or priority of the second onset relative to a condition in which both of the onset distractors were presented concurrently (double-onset conditions in Experiment 2 and in Experiment 1). However, this procedure failed to increase the number of second saccades to an onset. Saccades were made to the second onsets on less than $1 \%$ of the trials on which the eyes were initially directed to an onset on either the movement-contingent or stop-contingent trials.

Therefore, it would appear that multiple onset prioritization does not occur in singleton search. It seems likely that this is the result of increasing top-down activation or prioritization of the uniquely defined target on trials on which the first saccade was directed to an onset distractor. This interpretation is consistent with the relatively brief fixation durations on trials in which the eyes were initially directed to an onset distractor (113 $\mathrm{msec}$ and $108 \mathrm{msec}$ in Experiments 1 and 2, respectively), which suggests that the reflexive saccade to the onset and the goal-directed saccade to the singletontarget are programmed in parallel (Becker \& Jurgens, 1979; Irwin, Colcombe, et al., 2000; Kramer et al., 1999, 2000; Theeuwes et al., 1998; Theeuwes et al., 1999). That is, it would appear that the activation accorded to the delayed onset is insufficient to override the increasing activation of the singleton target that accrues even during an initial saccade to an onset distractor (i.e., as the programming of the next saccade to the singleton target is underway).

There are at least two other ways in which the appearance of the delayed onset might, in principle, detrimentally impact subjects' performance. First, on those trials in which the eyes are initially directed to an onset distractor, a subject's subsequent saccade to the singleton target might be delayed as might their manual response to the target. However, the saccade data presented in Table 4 belies this possibility since saccadic latency to make a second saccade to the singleton target was just as fast in the contingent conditions as in the double-onset condition. RTs were also statistically equivalent on the delayed $(885 \mathrm{msec})$ and dual-onset trials $(879 \mathrm{msec})$ for those trials in which the eyes first went to an onset distractor. Second, it is possible that the occurrence of a delayed second onset might slow processing of the singleton target on those trials in which the eyes went directly to the target. This could occur if attention, but not the eyes, is drawn to the onset location. However, this does not appear to be the case. The RTs for the delayed and double-onset conditions when the eyes went directly to the target were 755 and $757 \mathrm{msec}$, respectively. Therefore, it appears that the delayed occurrence of the second onset neither led to capture of the subjects' eyes nor to a detrimental influence on the processing of the target.

An interesting finding in the present study, which was consistent with the marginally significant trend in Experiment 1, was evidence for cancellation of a saccade to the onset distractors when two onsets were simultaneously presented in the display. There was an average, across Experiments 1 and 2, of $4.5 \%$ fewer saccade to an onset distractor on double than on single onset trials. This cancellation effect may be accounted for, in part, by a center of gravity effect. That is, in Experiment 2, a small but significant number of trials on which two onsets were concurrently presented resulted in an initial saccade to the (nononset) distractor located directly between the onsets. However, the center-of-gravity effect certainly does not account for the magnitude of the cancellation effect demonstrated in the two studies since (1) a center-ofgravity effect was not observed in Experiment 1 and (2) the center-of-gravity effect was quite small in Experiment 2. Therefore, it would appear that the cancellation effect was the result of a combination of saccades misdirected 
to a location/distractor between the two onsets as well as a true cancellation of reflexive saccades on the doubleonset trials.

\section{EXPERIMENT 3}

The results obtained in Experiments 1 and 2 clearly indicate that multiple onset prioritization does not occur in singleton search, at least not in paradigms in which eye movements are required to search a display for a predefined target stimulus. We have argued that the different pattern of results in our studies as compared with the research of Yantis and colleagues (Yantis \& Johnson, 1990; Yantis \& Jones, 1991), who found evidence for multiple onset prioritization with nonsingleton search, is likely due to the stronger and more reliable guidance of attention and the eyes through both top-down and bottom-up routes when a clearly defined target (i.e., a singleton) is present (Treisman \& Sato, 1990; Wolfe, 1994).

There is, however, an alternative explanation for the different pattern of results in the present studies and those of Yantis and colleagues (Yantis \& Johnson, 1990; Yantis \& Jones, 1991) In Yantis's studies, the target and distractors were sufficiently large so that eye movements were not necessary. In our studies, the stimuli were designed so that eye movements were required to perform the tasks. This was done to enable us to utilize eye movements to examine the phenomenon of capture.

One could suggest, however, that it is the need to make saccades rather than the distinction between singleton and nonsingleton search that limited the ability of multiple onsets to capture attention in our paradigm. This could occur, for example, if there is a limitation in number of saccades that can be programmed in parallel. That is, if subjects can only program one voluntary saccade (to the target) and one reflexive saccade (to an onset distractor) in parallel (Kramer et al., 2000; McPeek, Skavenski, \& Nakayama, 2000; Theeuwes et al., 1998), it would not be surprising that the second onset distractor did not capture the eyes in our task. However, this seems unlikely given previous demonstrations that subjects can plan a sequence of up to five saccades before moving their eyes (Zingale \& Kowler, 1987).

Another related possibility concerns the amount of time required to program a saccade versus the amount of time necessary to shift covert attention. Saccade programming takes approximately $150 \mathrm{msec}$ (Becker, 1991; Findlay, 1997; Salthouse \& Ellis, 1980), whereas the time to shift covert attention is likely to be considerably shorter (Czerwinski, Lightfoot, \& Shiffrin, 1992; Eriksen \& Yeh, 1985; Kroese \& Julesz, 1989; but see Ward, Duncan, \& Shapiro, 1996). Therefore, it is conceivable that although attention may visit the location of multiple onset distractors before being directed to the target, the slower pace of eye movement programming and execution may preclude multiple onset prioritization.

On the basis of these considerations it would appear prudent to examine whether our failure to find evidence suggestive of multiple onset prioritization is the result of more efficient guidance of attention to the target in singleton than in nonsingleton search or instead to the requirement that subjects move their eyes to search the display in our paradigm. To this end, we repeated Experiment 1 in every respect except for the size of the target and distractors. The stimuli were rendered sufficiently large (six Xs the size of the target and distractor stimuli in Experiment 1) so that the subjects could perform the task without making an eye movement. Indeed, the subjects were told explicitly not to move their eyes, and compliance was monitored with the same eye tracker used in the previous studies.

If our failure to observe evidence of multiple onset prioritization in Experiments 1 and 2 was the result of enhanced top-down and bottom-up guidance of attention to the singleton target, we would also expect to find a similar pattern of RT results in Experiment 3. That is, the RT difference between onset and nononset control trials would not be expected to be any larger in the dual than in the single onset trials. On the other hand, if our failure to observe evidence of multiple onset prioritization in the previous experiments was due to the need for subjects to move their eyes to locate and identify the target, we should find a larger RT difference (i.e., onset minus control) for the dual than for the single onset conditions in Experiment 3 , since eye movements were not necessary in this experiment.

\section{Method}

Subjects. Subjects were 8 University of Illinois students (4 male, 4 female). Three additional subjects participated in the experiment but were unable to keep their eyes focused in the center of the display on at least $75 \%$ of the experimental trials. These subjects were dropped from the study. The average age of the 8 subjects who successfully completed the study was 25.8 years with a range of 18 to 35 years. All subjects reported normal or corrected-to-normal vision.

Apparatus. The apparatus was the same as that employed in Experiment 1.

Stimuli. The stimuli were the same as those used in Experiment 1 with the following exception: Each of the circles that were arrayed around the circumference of the imaginary circle centered on fixation contained figure-eight premasks that were $2.4^{\circ} \times 1.2^{\circ}$ of visual angle in size.

Procedure. The procedure was the same as that employed in Experiment 1 with the following exception: Subjects were instructed to perform the task without moving their eyes, and their compliance with these instructions was monitored with the eye tracker.

Design. The design was the same as that employed in Experiment 1 .

\section{Results}

Discarded data. The first block of trials for each session was considered a practice block, and therefore those data were not included in the analyses. Of the remaining trials, $1.9 \%$ (range of 0 to $11 \%$ across the 8 subjects) were removed due to eye movements away from the center of the display, $4.2 \%$ of the trials due to incorrect responding, and $0.11 \%$ were removed because the RT was less than $100 \mathrm{msec}$. 
Table 5

Mean Reaction Times and Standard Deviations (in Milliseconds) for Onset and Nononset Distractors in Each Condition in Experiment 3

\begin{tabular}{|c|c|c|c|c|}
\hline \multirow[b]{3}{*}{ Trial Type } & \multicolumn{4}{|c|}{ Condition } \\
\hline & \multicolumn{2}{|c|}{ Abrupt Onset } & \multicolumn{2}{|c|}{ No Onset } \\
\hline & RT & $S D$ & RT & $S D$ \\
\hline Double $150^{\circ}-90^{\circ}$ & 785 & 111 & 777 & 107 \\
\hline Double $90^{\circ}-90^{\circ}$ & 803 & 108 & 769 & 121 \\
\hline Single $150^{\circ}$ & 786 & 118 & 738 & 94 \\
\hline Single $90^{\circ}$ & 816 & 125 & 731 & 82 \\
\hline
\end{tabular}

Manual RT. Mean RTs and SDs are presented in Table 5. The data were analyzed with a two-way repeatedmeasures ANOVA with trial type (single-90, single-150, double 90-90, or double 150-90) and condition (onset or nononset) as within-subjects factors. RTs were slower overall when sudden onsets appeared in the display than when the additional circles were not sudden onsets $[F(1,7)=53.0, p<.01]$. There was also a marginally significant interaction between condition and trial type $[F(3,21)=3.0, p<.06]$. As can be seen in Table 5, the difference between onset and nononset trials was smallest in the double 150-90, intermediate in the double 90-90 and single- 150 conditions, and largest in the single-90 condition.

Accuracy was uniformly high, exceeding $95 \%$ in all conditions and trial types. Although accuracy was slightly lower on onset trials (95.4\%) as compared with the nononset trials $(96.2 \%)$, the difference was not statistically significant. No other main effects or interactions were significant for response accuracy.

\section{Discussion}

The main question addressed in Experiment 3 was whether evidence for multiple onset prioritization would be obtained when the subjects could search the display for the target with covert attention rather than being required to move their eyes to identify the target as in Experiments 1 and 2. This question was addressed in Experiment 3 by increasing the size of the target and distractor stimuli six Xs compared with the stimulus size used in Experiments 1 and 2 and by instructing the subjects not to move their eyes during an experimental trial.

Evidence in support of multiple onset prioritization would be indicated by a larger onset cost (i.e., onset cost $=$ onset trial RT minus nononset control trial RT) when two rather than one onset was present in the display. This follows since it would be expected to take longer to direct covert attention to the singleton target if attention is first directed to two rather than one onset distractor (see Yantis \& Johnson, 1990; Yantis \& Jones, 1991).

As indicated in Table 5, this clearly was not the case. Indeed, the onset cost was smaller for the double 150-90 condition than for the other three conditions. ${ }^{3}$ Thus, the results of the present experiment when viewed in conjunction with Experiments 1 and 2 would appear to sug- gest that it is the enhanced top-down and bottom-up guidance of attention engendered by the singleton target rather than the requirement to make saccades that precludes multiple onset prioritization.

\section{GENERAL DISCUSSION}

The present study suggests that although onset distractors do indeed capture attention and the eyes, even when they are task-irrelevant, multiple onsets do not have an advantage over nononset objects during visual search for singleton targets. As such these results extend our recent research on oculomotor and attentional capture with single new but task-irrelevant objects (Irwin, Colcombe, et al., 2000; Kramer et al., 1999, 2000; Theeuwes et al., 1998; Theeuwes et al., 1999) and in Yantis and colleagues (Yantis \& Johnson., 1990; Yantis \& Jones, 1991) studies of stimulus-driven attentional prioritization.

The present results also suggest that targets that can be clearly distinguished from distractors, such as the color singleton target employed in the present study, engender strong top-down and bottom-up activation (Treisman \& Sato, 1990; Wolfe, 1994), which results in the prioritization of these objects for processing. Although the magnitude of the activation accorded to a singleton target is not always sufficient to overcome stimulus driven attentional capture, as evidenced by the approximately $25 \%$ of the trials on which the eyes were directed to an onset distractor in Experiments 1 and 2, capture of attention appears to be limited to single events (i.e., single onsets in the present case) and to be transitory in nature. That is, reorientation of attention and the eyes appears to occur rather rapidly, as is evidenced by brief fixation durations on the onset distractors on occasions when they are misdirected by a stimulus-driven event.

Our results also speak to another interesting and important issue, the relationship between covert and overt attention. It is clearly the case that we can shift attention independently of the eyes (Eriksen \& Yeh, 1985; Posner, 1980). However, research that has examined the relationship between covert attention and overt attention (i.e., via saccades) in free viewing situations has, in general, found a close coupling between saccade programming and covert attention. For example, Deubel and Schneider (1996) found that letter identification performance was best when the letter to be identified was also the target of a saccade. Similarly, Hoffman and Subramaniam (1995) had subjects detect a visual target just prior to making a saccade and found that detection performance was best when the location of the target and the subsequent saccade were the same (see also Henderson \& Hollingworth, 1999; Kowler, Anderson, Dosher, \& Blaser, 1995; Sheliga, Craighero, Riggio, \& Rizolatti, 1997; Sheliga, Riggio, \& Rizolatti, 1995; Shepherd, Findlay, \& Hockey, 1986; see Klein, 1980, and Remington, 1980, for exceptions to this pattern of results). Furthermore, a number of recent positron emission tomography (PET) and func- 
tional magnetic resonance imaging (fMRI) studies have reported highly overlapping activation patterns in the brain during covert and overt attentional tasks (Corbetta, 1998; Nobre, Gitelman, Dias, \& Mesulam, 2000). Thus, in summary, it would appear that attention often precedes saccades to locations in the visual field.

However, it is important to point out that the studies that have examined the relationship between covert and overt attention have done so in situations in which subjects voluntarily or endogenously shifted their attention (and eyes) around a display. The question of whether covert and overt attention are closely coupled during involuntary or exogenous shifts of attention (and the eyes) has received little study and those few studies that have been conducted have produced somewhat mixed findings (Irwin, Brockmole, \& Kramer, 2000; Kustov \& Robinson, 1996; Mokler \& Fischer, 1999).

The similar patterns of RT results, for the single- and dual-onset conditions, found in Experiments 1 and 2, in which eye movements were required, and Experiment 3 , in which eye movements were unnecessary, suggest a close coupling between overt and covert attention even during involuntary allocation of attention. Another aspect of the data suggests a similar conclusion. If covert attention could be dissociated from saccades in the first two experiments, one might expect that RTs would be shorter on trials in which an onset was presented and the eyes went directly to the singleton target as compared with the nononset control trials. This follows if one assumes that covert attention might be deployed to an onset distractor even if overt attention (i.e., the eyes) is deployed directly to the target. However, RTs obtained on trials in which an onset was present and the eyes went directly to the target (i.e., $832 \mathrm{msec}$ and $757 \mathrm{msec}$ in Experiments 1 and 2, respectively) were not significantly longer than RTs obtained on nononset control trials in the two studies (i.e., $834 \mathrm{msec}$ and $774 \mathrm{msec}$ in Experiments 1 and 2, respectively). Thus, these data also support the proposal of a close coupling of covert and overt attention when attention is involuntarily captured.

Of course, additional research with converging operations will be necessary to further examine the relationship between overt and covert aspects of exogenous attention and to establish its boundary conditions. Indeed, such research might employ techniques such as Eriksen and Yeh's (1985) response compatibility paradigm to determine if compatibility effects (i.e., longer RTs when a distractor is incompatible than when a distractor is compatible with the response of a target) are obtained from task-irrelevant onset distractors whether or not the eyes are directed to them. Behavioral (Hoffman, Nelson, \& Houck, 1983; Kim \& Cave, 1999) or electrophysiological (Bruin, Kenemans, Verbaten, \& Van der Heijden, 1998; Weber, Kramer, \& Miller, 1997) probe paradigms might also be employed in an effort to determine whether covert attention had been deployed to the location of an onset distractor whether or not an eye movement was directed to its location.

\section{REFERENCES}

Aitsebaomo, A. P., \& Bedell, H. E. (2000). Saccadic and psychophysical discrimination of double targets. Optometry \& Vision Science, 77, 321-330.

BECKER, W. (1991). Saccades. In R. H. Carpenter (Ed.), Eye movements (pp. 95-137). Boston: CRC Press.

BECKER, W., \& JuRgens, R. (1979). An analysis of the saccadic systems by means of double-step stimuli. Vision Research, 19, 967-983.

Bruin, K. J., Kenemans, J. L., Verbaten, M. N., \& Van der Heijden, A. H. C. (1998). Localization of spatial attentional processes with the aid of a probe technique. Electroencephalography \& Clinical Neurophysiology: Evoked Potentials, 108, 110-122.

Conbetta, M. (1998). Frontoparietal cortical networks for directing attention and the eye to visual locations: Identical, independent, or overlapping neural systems. Proceedings of the National Academy of Science, 95, 831-838.

Czerwinski, M., Lightfoot, N., \& Shiffrin, R. M. (1992). Automatization and training in visual search. American Journal of Psychology, 105, 271-315.

Deubel, H., \& Schneider, W. (1996). Saccade target selection and object recognition: Evidence for a common attentional mechanism. $\mathrm{Vi}$ sion Research, 6, 1827-1837.

ERIKSEN, C. W., \& YeH, Y. Y. (1985). Allocation of attention in the visual field. Journal of Experimental Psychology: Human Perception \& Performance, 11, 583-597.

FINDLAY, J. M. (1997). Saccade target selection during visual search. Vision Research, 37, 617-631.

Folk, C. L., \& Remington, R. (1998). Selectivity in distraction by irrelevant featural singletons: Evidence for two forms of attentional capture. Journal of Experimental Psychology: Human Perception \& Performance, 24, 847-858.

Folk, C. L., \& Remington, R. (1999). Can new objects override attentional control settings? Perception \& Psychophysics, 61, 727-739.

Folk, C. L., Remington, R., \& Johnston, J. C. (1992). Involuntary covert orienting is contingent in attentional control settings. Journal of Experimental Psychology: Human Perception \& Performance, 18, 1030-1044.

Folk, C. L., Remington, R., \& Johnston, J. C. (1993). Contingent attention capture: A reply to Yantis (1993). Journal of Experimental Psychology: Human Perception \& Performance, 19, 682-685.

Folk, C. L., Remington, R., \& WRight, J. H. (1994). The structure of attentional control: Contingent attentional capture by apparent motion, abrupt onset, and color. Journal of Experimental Psychology: Human Perception \& Performance, 20, 317-329.

Henderson, J. M., \& Ferreira, F. (1990). Effects of foveal processing difficulty on the perceptual span in reading: Implications for attention and eye movement control. Journal of Experimental Psychology: Learning, Memory, \& Cognition, 16, 417-429.

Henderson, J. M., \& Hollingworth, A. (1999). The role of fixation position in detecting scene changes across saccades. Psychological Science, 10, 438-443.

Hillstrom, A. P., \& Yantis, S. (1994). Visual motion and attentional capture. Perception \& Psychophysics, 55, 399-411.

Hoffman, J. E., Nelson, B., \& HoucK, M. R. (1983). The role of attentional resources in automatic detection. Cognitive Psychology, 51, $379-410$.

Hoffman, J. E., \& Subramaniam, B. (1995). The role of visual attention in saccadic eye movements. Perception \& Psychophysics, 57, 787-795.

Irwin, D. E., Brockmole, J., \& Kramer, A. F. (2000, June). Attentional and oculomotor capture in the antisaccade paradigm. Paper presented at the Conference on Attention Distraction and Action. Villanova, PA.

Irwin, D. E., Colcombe, A. M., Kramer, A. F., \& Hahn, S. (2000). Attentional and oculomotor capture by onset, luminance, and color singletons. Vision Research, 40, 1443-1458.

KIM, M.-S., \& CAVE, K. R. (1999). Top-down and bottom-up attentional control: On the nature of interference from a salient distractor. Perception \& Psychophysics, 61, 1009-1023. 
KLEIN, R. (1980). Does oculomotor readiness mediate cognitive control of attention? In R. S. Nickerson (Ed.), Attention \& performance VIII (pp. 259-276). Hillsdale, NJ: Erlbaum.

Kowler, E., Anderson, E., Dosher, B., \& Blaser, E. (1995). The role of attention in the programming of saccades. Vision Research, $\mathbf{3 5}$, $1897-1916$

Kramer, A. F., Hahn, S., Irwin, D. E., \& Theeuwes, J. (1999). Attentional capture and aging: Implications for visual search performance and oculomotor control. Psychology \& Aging, 14, 135-154.

Kramer, A. F., Hahn, S., Irwin, D. E., \& Theeuwes, J. (2000). Age differences in the control of looking behavior: Do you know where your eyes have been? Psychological Science, 11, 210-217.

Kroese, B., \& Julesz, B. (1989). The control and speed of shifts in attention. Vision Research, 29, 1607-1619.

Kustov, A. A., \& Robinson, D. L. (1996). Shared neural control of attentional shifts and eye movements. Nature, 384, 74-77.

Martin-Emerson, R, \& Kramer, A. F. (1997). Offset transients modulate attentional capture by sudden onsets. Perception \& Psychophysics, 59, 739-751.

McPeek, R. M., Skavenski, A. A., \& Nakayama, K. (2000). Concurrent processing of saccades in visual search. Vision Research, 40, 2499-2516.

Miller, J. (1989). The control of attention by abrupt visual onsets and offsets. Perception \& Psychophysics, 45, 567-571.

Mokler, A., \& Fischer, B. (1999). The recognition and correction of involuntary prosaccades in an antisaccade task. Experimental Brain Research, 125, 511-516.

Nobre, A. C., Gitelman, D. R., Dias, E. C., \& Mesulam, M. M. (2000). Covert visual spatial orienting and saccades: Overlapping neural systems. NeuroImage, 11, 210-216.

Posner, M. (1980). Orienting of attention. Quarterly Journal of Experimental Psychology, 32, 3-25.

Reichle, E. D., Pollatsek, A., Fisher, D. L., \& Rayner, K. (1998). Toward a model of eye movement control in reading. Psychological Review, 105, 125-157.

Remington, R. W. (1980). Attention and saccadic eye movements. Journal of Experimental Psychology: Human Perception \& Performance, 6, 726-744.

Remington, R. W., Johnston, J. C., \& Yantis, S. (1992). Involuntary attentional capture by abrupt onsets. Perception \& Psychopysics, 51, 279-290.

Salthouse, T. A., \& Ellis, C. L. (1980). Determinants of eye fixation duration. Journal of Psychology, 93, 207-234.

Sheliga, B. M., Craighero, L., Riggio, L., \& Rizolatti, G. (1997). Effects of spatial attention on directional manual and ocular responses. Experimental Brain Research, 114, 339-351.

Sheliga, B. M., Riggio, L., \& Rizolatti, G. (1995). Spatial attention and eye movements. Experimental Brain Research, 105, 261-275.

Shepherd, M., Findlay, J. M., \& Hockey, R. J. (1986). The relationship between eye movements and spatial attention. Quarterly Journal of Experimental Psychology, 38A, 475-491.

Theeuwes, J. (1991). Exogenous and endogenous control of attention: The effect of visual onsets and offsets. Perception \& Psychophysics, 49, 83-90.

Theeuwes, J., Kramer, A. F., Hahn, S., \& Irwin, D. E. (1998). Our eyes do not always go where we want them to go: Capture of the eyes by new objects. Psychological Science, 9, 379-385.

Theeuwes, J., Kramer, A. F., Hahn, S., Irwin, D. E., \& Zelinsky, G. J. (1999). Influence of attentional capture on eye movement control. Journal of Experimental Psychology: Human Perception \& Performance, 25, 1595-1608.

Treisman, A., \& Sato, S. (1990). Conjunction search revisited. Jour- nal of Experimental Psychology: Human Perception \& Performance, 16, 459-478.

Viviani, P., \& Swensson, R. G. (1982). Saccadic eye movements to peripherally discriminated visual targets. Journal of Experimental Psychology: Human Perception \& Performance, 8, 113-126.

Ward, R., Duncan, J., \& Shapiro, K. (1996). The slow time course of visual attention. Cognitive Psychology, 30, 79-109.

Weber, T., Kramer, A. F., \& Miller, G. (1997). Selective processing of superimposed objects: An electrophysiological analysis of objectbased attentional selection. Biological Psychology, 45, 159-182.

Wolfe, J. M. (1994). Guided Search 2.0: A revised model of visual search. Psychonomic Bulletin \& Review, 1, 202-238.

YANTIS, S. (1996). Attentional capture in vision. In A. F. Kramer, M. G. H. Coles, \& G. D. Logan (Eds.), Converging operations in the study of visual selective attention (pp. 45-76). Washington, D.C.: American Psychological Association.

Yantis, S., \& Hillstrom, A. P. (1994). Stimulus-driven attentional capture: Evidence from equiluminant visual objects. Journal of Experimental Psychology: Human Perception \& Performance, 20, 95107.

YANTIS, S., \& Johnson, D. N. (1990). Mechanisms of attentional priority. Journal of Experimental Psychology: Human Perception \& Performance, 16, 812-825.

YANTIS, S., \& JoNES, E. (1991). Mechanisms of attentional selection: Temporally modulated priority tags. Perception \& Psychophysics, 50, 166-178.

YANTIS, S., \& JonidES, J. (1984). Abrupt visual onsets and selective attention: Evidence from visual search. Journal of Experimental Psychology: Human Perception \& Performance, 10, 601-621.

YANTIS, S., \& Jonides, J. (1990). Abrupt visual onsets and selective attention: Voluntary versus automatic allocation. Journal of Experimental Psychology: Human Perception \& Performance, 16, 121-134.

Zingale, C. M., \& Kowler, E. (1987). Planning sequences of saccades. Vision Research, 27, 1327-1341.

\section{NOTES}

1. It should be noted that previous analyses involving eye path were conducted using a $\pm 30^{\circ}$ criterion. Because of the proximity of the distractor circles to the center-of-gravity location in the double 150-90 condition, such a criterion would have resulted in overlapping of saccades coded as to distractor and to center of gravity. To alleviate this problem, a $\pm 15^{\circ}$ criterion was used for this analysis.

2 . The power to detect a difference of $4.5 \%$ between the single- and double-onset trials in Experiment 1 was quite low, .15. Therefore, we thought it prudent to substantially increase the number of subjects in Experiment 2 in order to determine if the nonsignificant trend observed in Experiment 1 would become reliable.

3 . It is not completely clear why the onset cost was substantially smaller in the double 150-90 condition than in the other three conditions. However, one possibility, which is illustrated in Figure 1, is that the onset distractors are relatively close together (i.e., $60^{\circ}$ apart) in the double 150-90 conditions. Thus, cancellation of attentional capture might be expected under such conditions (Yantis \& Johnson, 1990, Model 1). In any event, the important point is that double onsets did not produce a larger RT cost than did single onsets, suggesting that it is unlikely that the discrepancy in the results between the present study and Yantis and colleagues studies is the requirement for subjects to make eye movements in Experiments 1 and 2.

(Manuscript received February 1, 2000; revision accepted for publication October 16, 2000.) 